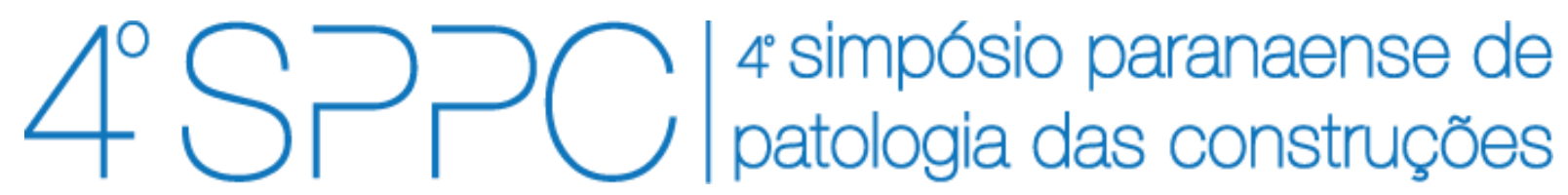

ISSN 2526-7248 artigo n. 4SPPC107, pp. 48-58, 2019

\title{
Estudo de Caso da Reabilitação de um Edifício Multipavimentos Paralisado por 4 Anos na Cidade de Joinville-SC
}

\author{
Dranka, Jayne ${ }^{1}$; Minikowski, Wagner ${ }^{2}$ \\ ${ }^{1}$ Graduanda em Engenharia Civil, Universidade do Estado de Santa Catarina, \\ jaynedranka@gmail.com \\ 2 Professor Engenheiro Civil Especialista, Universidade do Estado de Santa \\ Catarina, wagner.minikowski@udesc.br
}

\begin{abstract}
Resumo: As construções, apesar de serem aprimoradas desde a antiguidade, apresentam manifestações patológicas devido a problemas que surgem por falhas na execução, baixa qualidade do material e ação do ambiente. Obras inacabadas e abandonadas são propensas à manifestações patológicas e, pela falta de tratamento imediato, comprometem a construção já existente. O presente estudo de caso permitiu a análise da viabilidade para que uma obra paralisada por 4 anos em Joinville - SC entrasse em fase de reabilitação, fosse recuperada e concluída. Foram levantados os pontos afetados nos serviços de estrutura, alvenaria de vedações, revestimento argamassado e instalações prediais. Realizaram-se visitas à obra e entrevistas com o responsável técnico pela execução. Foram estudadas as soluções para a recuperação dos pontos atingidos e feita uma relação com base em literaturas, possibilitando a compreensão da viabilidade da reabilitação. Os métodos adotados pelo responsável técnico foram compatíveis com a bibliografia.
\end{abstract}

Palavras-chave: paralisação, reabilitação, construção civil, patologia.

\begin{abstract}
Although it has been improving since antiquity, constructions often present pathological manifestations, problems that arise due to flaws in the execution, low quality of the material and actions of the environment, thus requiring repairs to allow the good performance of the building. Unfinished and abandoned construction sites have ideal characteristics for the appearance of pathological manifestations and, by not having an immediate treatment, increasingly compromising what has already been constructed. The presented case study made possible the feasibility analysis so that a construction that has been paralyzed for 4 years in Joinville - SC could enter the rehabilitation phase to recover and give continunity to the initial project with the appropriate improvements. The points affected in the services of foundation, structure, masonry of fences, mortar coating and building facilities were raised. Visits to the site and interviews with the technical responsible for the execution were made. The solutions adopted for the recovery of the affected points were studied and a bibliography was researched, enabling the understanding of the feasibility of rehabilitation of the construction. The methods adopted by the technician responsible for the work were compatible with the bibliography.
\end{abstract}

Keywords: shutdown, rehabilitation, construction, pathology. 
DRANKA, J; MINIKOWSKI, W. ESTUDO DE CASO DA REABILITAÇÃO DE UM EDIFÍCIO MULTIPAVIMENTOS PARALISADO POR 4 ANOS NA CIDADE DE JOINVILLE-SC. $4^{\circ}$ Simpósio Paranaense de Patologia das Construções (40 SPPC), artigo 4SPPC107, pp. 48 - 58, 2019. DOI: $10.4322 / 2526-7248.028$

\section{Introdução}

Não é difícil encontrar obras em estado de abandono, ou melhor, de paralisação. Os motivos que levam a não finalização de uma obra são muitos, mas uma dúvida que geralmente acaba surgindo é se há a possibilidade de retomada da construção ou se a única saída é a demolição.

O grande número de manifestações patológicas nas construções, abandonadas ou não, coloca em questionamento a durabilidade e excelência do desempenho de estruturas, especialmente de concreto armado. Estudos, normas e recomendações visam a diminuição das ocorrências, mas segundo alguns estudos, na prática, erros e deficiências de projetos, materiais inadequados, mão de obra desqualificada e falta de controle de qualidade da obra continuam afetando o desempenho e durabilidade das edificações [1].

O presente estudo de caso visou estudar o processo de reabilitação de um edifício multipavimentos que esteve paralisado por quatro anos na cidade de Joinville - SC, bem como analisar os pontos afetados pela paralisação da obra e as soluções adotadas para a recuperação.

\section{Materiais e Métodos}

Para a realização deste trabalho, o método utilizado foi a pesquisa bibliográfica e o estudo de caso qualitativo. A revisão da literatura foi por meio de bibliotecas e pelo portal de periódicos da Coordenação de Aperfeiçoamento de Profissional de Nível Superior - CAPES. O estudo de caso qualitativo foi realizado em uma obra denominada "A", em processo de reabilitação, que se situa na região central da cidade de Joinville, Santa Catarina, Brasil.

A edificação de concreto armado possui 2 pavimentos garagem e 10 pavimentos tipo com 8 apartamentos residenciais por pavimento. No pavimento térreo está previsto uso para garagem e salas comerciais. A obra esteve paralisada por 4 anos e possuía serviços de fundação, estrutura e alvenaria de vedações executados totalmente e os serviços de revestimento argamassado e instalações prediais executados parcialmente. $O$ gerenciamento técnico da obra foi feito pela empresa $X$ de engenharia e consultoria, com um responsável técnico pela execução.

Em campo, foram feitas visitas a obra com entrevistas ao técnico responsável pela execução da reabilitação, registro fotográfico da situação do edifício causada pelo abandono da obra e registro dos pontos afetados pela paralização, bem como sua forma de recuperação. Foram analisados os serviços de estrutura, alvenaria de vedações, revestimento argamassado e instalações prediais do edifício.

\section{Manifestações Patológicas e Métodos de Recuperação}

$\mathrm{Na}$ engenharia, se utiliza o termo patologia no sentido de "tratamento dos problemas", com o objetivo de reabilitar a estrutura ou o objeto em estudo. A patologia possui o processo inicial de diagnóstico, onde se analisa o aparecimento de defeitos, buscando sua origem e causas. A segunda etapa corresponde a 
DRANKA, J; MINIKOWSKI, W. ESTUDO DE CASO DA REABILITAÇÃO DE UM EDIFÍCIO MULTIPAVIMENTOS PARALISADO POR 4 ANOS NA CIDADE DE JOINVILLE-SC. $4^{\circ}$ Simpósio Paranaense de Patologia das Construções (40 SPPC), artigo 4SPPC107, pp. 48 - 58, 2019. DOI: $10.4322 / 2526-7248.028$

terapia, onde se levanta condicionantes técnicos e econômicos e pode ser escolhida uma ação corretiva adequada ao problema [2].

Segundo Azevedo [2], os danos causados pelas manifestações patológicas aumentaram a preocupação com o tratamento e não aparição delas. Muitas construtoras vêm desenvolvendo e utilizando programas de qualidade para reduzir erros no processo de execução da obra. Percebe-se assim que há uma profunda relação da patologia com a qualidade e durabilidade das estruturas.

\subsection{Estrutura de Concreto Armado}

Em estruturas de concreto armado, as manifestações patológicas podem ocorrer na fase de concepção da estrutura, construção, entrega e uso [2]. As causas podem ser intrínsecas, relacionadas aos materiais e elementos utilizados e ações externas, ou extríncias, relacionadas com o comportamento estrutural da edificação [3-4].

As causas das manifestações na estrutura podem estar associadas à qualidade técnica das pessoas envolvidas no processo de construção. São exemplos de causas deste tipo de falhas a não capacitação da mão-de-obra, a falta de motivação da equipe e a falta de informação entre os setores da obra, bem como de informações técnicas para os trabalhadores da obra sobre os materiais a serem utilizados. As falhas humanas se enquadram nas causas intrínsecas de patologia [4].

\subsubsection{Corrosão da Armadura}

Durante a execução da estrutura, falhas na concretagem podem resultar em porosidade excessiva do concreto, ou, popularmente, "bicheiras". Elas podem ocorrer pela deficiência da composição do traço e da consistência do concreto, altura do lançamento do concreto, alta densidade de armaduras, problemas na vedação de formas e seu acabamento superficial e pela intensidade e quantidade de pontos de vibração [2].

A porosidade excessiva do concreto deixa o concreto segregado, ficando exposto a ação de agentes externos, podendo atingir as armaduras da estrutura. As armaduras expostas podem sofrer corrosão, que são reações de origem químicas ou eletroquímicas a partir da interação de um material com o meio ambiente, destruindo o material envolvido [5].

Armaduras que sofrem corrosão podem ser recuperadas, segundo Viana [5], Munaro e Possan [6], com a execução da limpeza das estruturas por meio de jato d'água sob pressão e escova de aço, remoção da camada superficial do concreto com a técnica de apicoamento e limpeza da barra corroída por meio de escovação manual, proteção ou substituição das camadas superficiais do concreto, recomposição do cobrimento das armaduras com argamassa polimérica e processos de cura úmida e impermeabilização da estrutura.

Os materiais utilizados para reparos superficiais geralmente são argamassas de reparo, concreto e grautes a base de cimento Porland. Estes materiais são amplamente aplicados por serem semelhantes aos materiais originais da peça que apresentou falhas de concretagem. É muito comum o uso de aditivos nestes 
DRANKA, J; MINIKOWSKI, W. ESTUDO DE CASO DA REABILITAÇÃO DE UM EDIFÍCIO MULTIPAVIMENTOS PARALISADO POR 4 ANOS NA CIDADE DE JOINVILLE-SC. $4^{\circ}$ Simpósio Paranaense de Patologia das Construções (40 SPPC), artigo 4SPPC107, pp. 48 - 58, 2019. DOI: 10.4322/2526-7248.028

materiais que possam inibir a corrosão, reduzir a contração, ainda podendo ser com adição de fibras de polipropileno, adições minerais e poliméricas [7]

\subsection{Alvenaria de Vedações}

As alvenarias de vedação são destinadas a compartimentar espaços, devendo suportar seu peso próprio e cargas de utilização. A alvenaria de vedação pode ser executada com o uso de tijolos cerâmicos, que são assentados com uma argamassa de assentamento. É recomendado o uso de argamassas mistas, compostas por cimento e cal hidratada [8].

É gerado umidade nos materiais que constituem a obra quando eles absorvem água. As manifestações mais recorrentes do problema de umidade na alvenaria são mancha de umidade, corrosão, bolor, fungos, algas, líquens, eflorescências, descolamentos de revestimentos, friabilidade da argamassa por dissolução de compostos com propriedades cimentíceas, fissuras e mudança de coloração dos revestimentos [8].

Quando o mofo se apresenta sobre tinta e reboco, podem ser aplicados produtos antimofo ou impermeabilizantes após a remoção da tinta, para possibilitar a penetração do produto nos poros do reboco. Caso haja infiltração e desplacamento do reboco, produtos mais fortes precisam ser utilizados. O bolor pode ser tratado da mesma forma que o mofo, geralmente sendo de mais fácil remoção, em alguns casos apenas com água. Para impedir a produção e reaparecimento de bolor e fungo, é importante controlar a umidade relativa do ambiente, mantendo a alvenaria seca e sem infiltrações e fazer a correta limpeza dos cômodos [9].

\subsection{Revestimento Argamassado}

Os revestimentos geralmente são constituídos de diversas camadas com diferentes materiais e ligadas entre si. Os métodos para execução são variados, mas o método convencional, segundo Taguchi [8], é composto por base de tijolos ou blocos de concreto e revestimento.

O revestimento é constituído por três camadas: chapisco, emboço e reboco. O chapisco promove aderência entre alvenaria e emboço, tendo acabamento mais áspero. $\mathrm{O}$ emboço tem a finalidade de regularizar a base para receber uma camada de reboco ou revestimento decorativo e proteger a construção. O reboco é a camada executada para receber revestimento decorativo ou ser o acabamento final. Portanto, é uma camada fina e dá proteção externa às paredes [8].

Segundo Taguchi [8], em todos os tipos de aplicações de revestimento argamassado podem aparecer manifestações patológicas de infiltração, descolamento do revestimento, desprendimento de cerâmica, bolor e desplacamento do revestimento de argamassa. Nos casos de desplacamento do revestimento de argamassa, ele ocorre pela perda de aderência com a camada anterior, seja por falhas desde o processo de mistura da argamassa e da execução da camada que será aderida até a combinação com outras manifestações patológicas como a umidade [8-9]. 
A forma de recuperação do desplacamento consiste em remover a argamassa que ficou sobre a superfície, a fim de limpá-la e permitir a aderência a uma nova camada. Na região do desplacamento ou em áreas que se desconfie de possível desplacamento, deve ser fazer um teste de percussão com martelo e mapeamento para descobrir onde o revestimento apresenta som cavo e então remover 0 revestimento desta região. Após limpeza da região, deve se recomeçar a execução do revestimento argamassado, eliminando os fatores que podem ter causado o desplacamento [8][10].

\subsection{Instalações Prediais}

Instalações prediais de água fria, água quente, esgoto sanitário, sistema de prevenção e proteção contra incêndio e aquecimento a gás apresentam manifestações patológicas por erros envolvendo projeto, compatibilização, mal uso, deterioração de materiais, infiltrações, problemas executivos e a qualidade dos materiais. As soluções para recuperação dos sistemas dependem da análise da situação e estudo específico para a recuperação, visando o adequado desempenho, resultando geralmente na revisão e adequação dos projetos conforme as normas existentes e as necessidades atuais e as instalações executadas de forma inadequadas ou deterioradas devem ser substituídas [11].

\section{Resultados e Discussões}

A partir dos dados da empresa, visitas à obra, busca na bibliografia e entrevistas com o profissional responsável pela execução da reabilitação, foram analisados os pontos afetados no edifício pela sua paralisação, as propostas de solução para estes pontos e os aspectos técnicos considerados para que fosse possível viabilizar a retomada da contrução do edifício, a fim de possibilitar a conclusão da edificação.

\subsection{Estrutura de Concreto Armado}

Nas fachadas do edifício, muitas vigas apresentavam corrosão da armadura na face externa por falha de concretagem (Fig. 1). O procedimento de recuperação adotado abrange as etapas propostas pelos autores Timermann [3], Munaro e Possan [6] e Grochoski [7], sendo elas a abertura da região afetada, limpeza completa da oxidação da armadura e aplicação de argamassa estrutural, recompondo a peça danificada.

Em alguns pilares da edificação, foi percebido que falhas na concretagem resultaram na exposição da armadura no pé dos pilares, em diferentes graus de corrosão e área de concreto desagregado. Os casos ocorreram principalmente nos primeiros pavimentos (Fig. 3 e Fig. 4).

O procedimento de recuperação adotado na obra condiz com o procedimento descrito por Viana [5], que também expõe fatores possíveis para a exposição da armadura com corrosão do aço. A manifestação pode ser pelas condições do ambiente, umidade do ambiente, traço do concreto, lançamento e adensamento e ainda o processo de cura. No caso da obra em estudo, falhas na concretagem levaram a porosidade excessiva do concreto, segregando-o e expondo a armadura na região inferior de alguns pilares. 


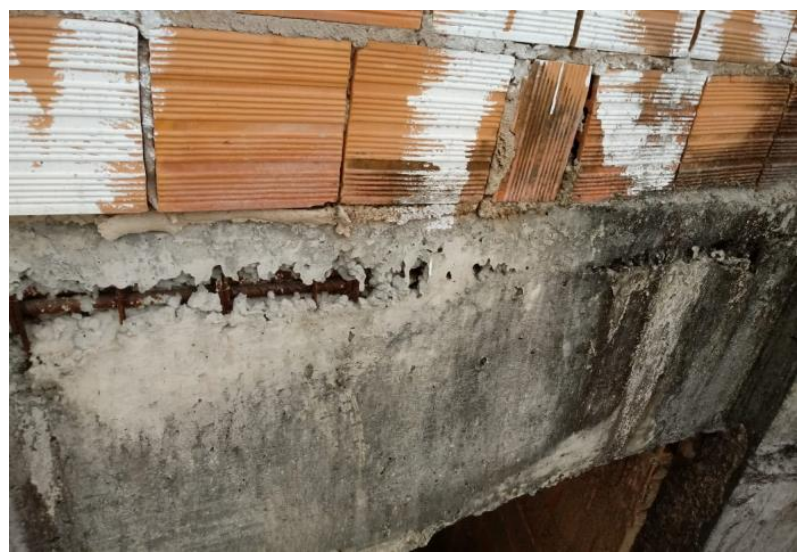

Figura 1: Viga externa com falha de concretagem.

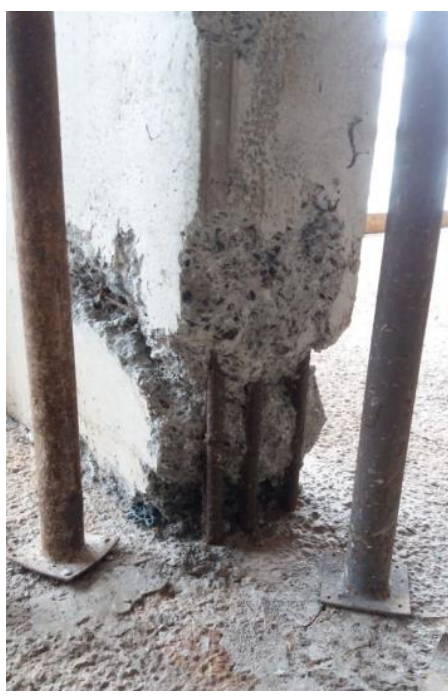

Figura 3: Exposição da armadura no pé do pilar.

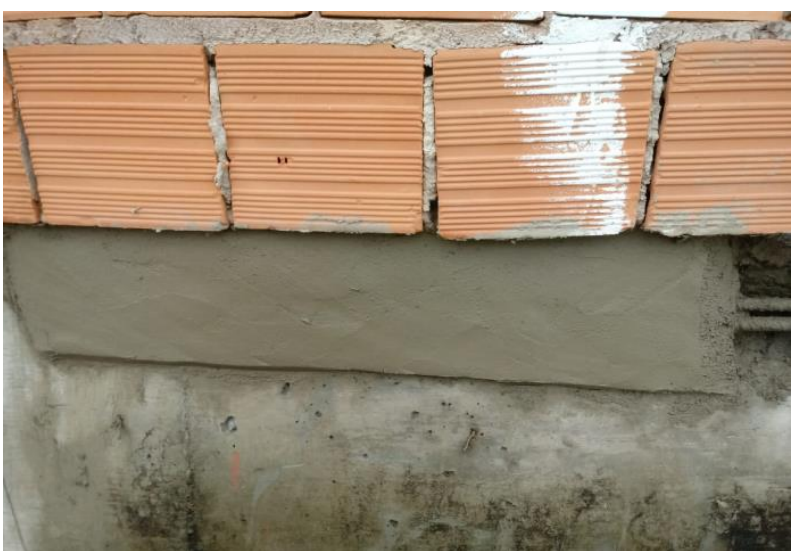

Figura 2: Viga externa após aplicação de argamassa estrutural.

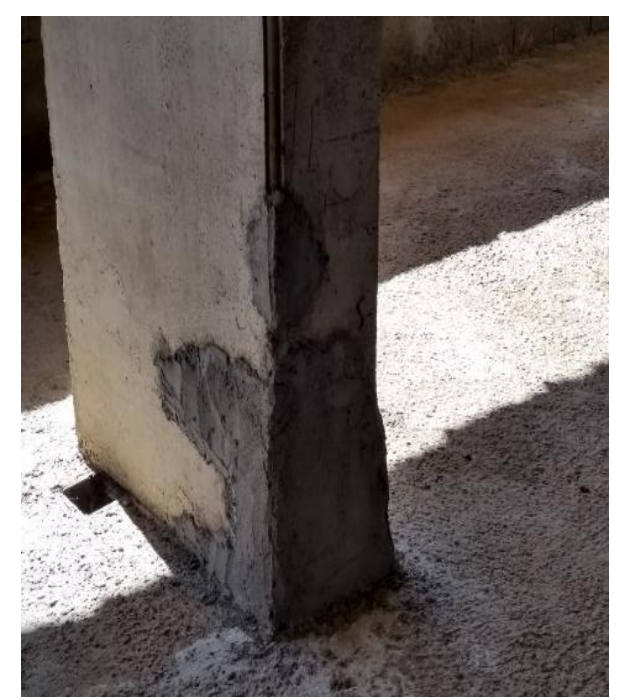

Figura 4: Pilar após recuperação.

$\mathrm{Na}$ parte inferior das lajes dos apartamentos, houve o desplacamento do revestimento argamassado em algumas regiões do teto (Fig. 5). Segundo verificações do responsável técnico da obra, os problemas ocorreram por falhas ainda na fase de limpeza e execução de chapisco do teto para permitir aderência entre as camadas. Como medida de segurança, foi inspecionado o revestimento do teto de toda a edificação com o teste de percussão para localizar outras áreas em que a aderência estava incorreta, com possibilidade de desplacamento do revestimento argamassado.

A recuperação das áreas será feita com a retirada do revestimento sem aderência adequada, limpeza do local, lixamento e repetição do processo, com camada de chapisco e emboço, garantindo a fixação e acabamento das camadas. Este método respeita as recomendações apresentadas por Taguchi [8], Pacheco e Vieira [10]. 


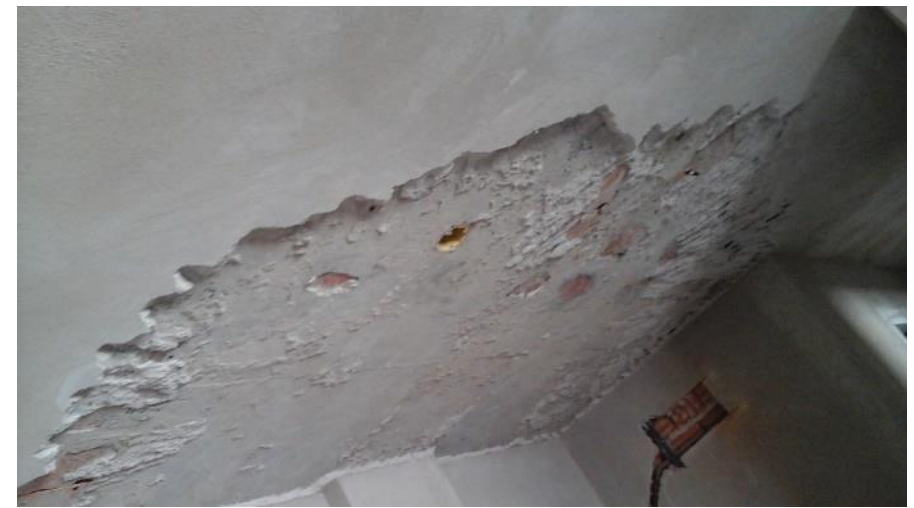

Figura 5: Desplacamento de revestimento argamassado em teto de apartamento.

\subsection{Alvenaria de Vedações}

Nas paredes de alvenaria dos apartamentos também ocorreram desplacamento de revestimento argamassado. Nas paredes com chapisco aparente, foi possível perceber a má qualidade de execução e falta de cobertura da camada por toda a parede para posterior camada de reboco (Fig. 6).

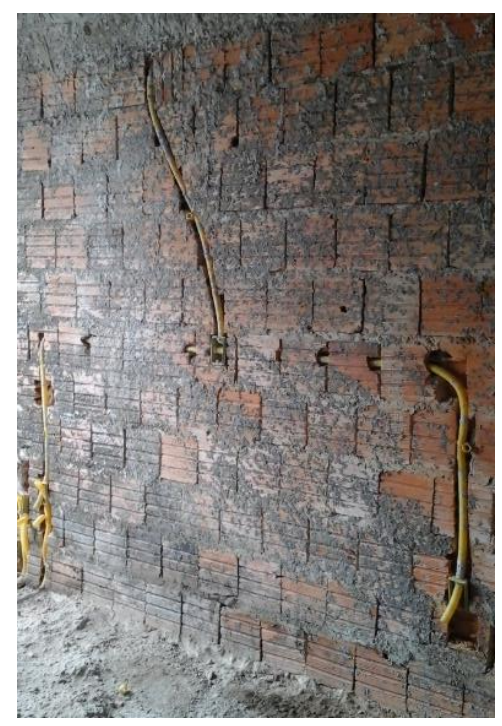

Figura 6: Chapisco executado antes da paralisação da obra.

O tempo de paralisação da obra, o clima úmido e as temperaturas médias elevadas da cidade de Joinville contribuíram para maior desenvolvimento de fungos e material orgânico nas paredes do edifício. Nas fachadas, a alvenaria se apresentou escura, com fungos e material orgânico, assim como nas paredes internas, mesmo nas que possuíam revestimento argamassado. Através de consultoria especializada para avaliação dos materiais presentes na fachada, foi identificada a presença de fungos pretos, vermelhos e verdes provenientes de estuários distintos nas proximidades de Joinville, somando-se à fuligem gerada por uma empresa de grande porte de fundição da cidade (Fig. 7). 
DRANKA, J; MINIKOWSKI, W. ESTUDO DE CASO DA REABILITAÇÃO DE UM EDIFÍCIO MULTIPAVIMENTOS PARALISADO POR 4 ANOS NA CIDADE DE JOINVILLE-SC. $4^{\circ}$ Simpósio Paranaense de Patologia das Construções (40 SPPC), artigo 4SPPC107, pp. 48 - 58, 2019. DOI: 10.4322/2526-7248.028

O responsável técnico da obra definiu como medida de recuperação a lavagem das paredes afetadas com produto de solução aquosa, composto por tensoativos de base vegetal, para limpar profundamente e evitar o surgimento de futuras proliferações de fungos, causando bolor e mofo, bem como a presença de material orgânico, como recomendado por Galdino et al. [9].

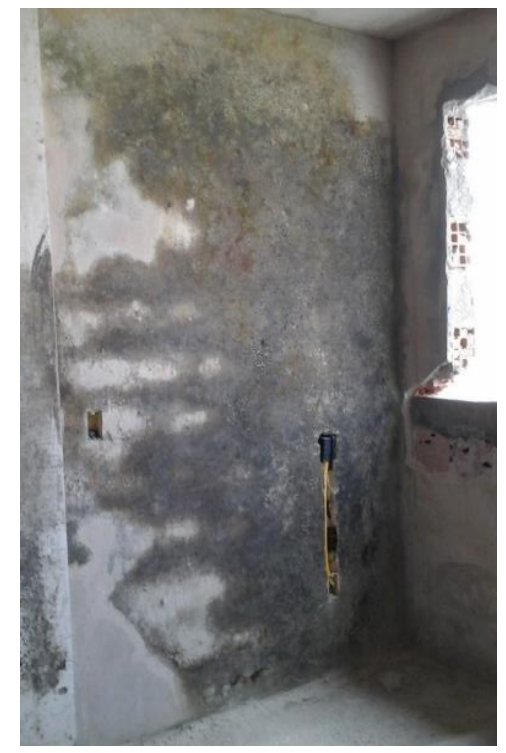

Figura 7: Manchas de fungos e matéria orgânica em parede interna de alvenaria.

\subsection{Instalações Prediais}

\subsubsection{Instalação Elétrica}

Após verificações do responsável técnico pela reabilitação, foi percebida a necessidade de atualização dos projetos elétricos, além de verificação do que já havia sido executado. Segundo Nascimento [11], as instalações elétricas têm sido cada vez mais solicitadas e novos equipamentos são incorporados ao cotidiano dos usuários, aumentando as cargas que o sistema precisa suportar, motivo a mais para que haja revisão e adequação de projetos elétricos decorrido um tempo entre sua concepção e real execução.

Foram encontrados eletrodutos flexíveis sobre o piso, inclusive com sobreposição. Muitos estavam danificados pela exposição ao tempo e a danos pela passagem de pessoas e equipamentos sobre eles. Alguns trechos necessitaram substituição e foi feita uma proteção mecânica com argamassa de cimento e areia, para evitar maiores danos até a aplicação da camada de contrapiso.

\subsubsection{Instalações Hidrossanitárias}

As instalações hidrossanitárias passaram por verificação para determinação de seu estado de conservação. A partir de quebra das paredes de alvenaria e abertura dos shafts, foi visto que a tubulação e conexões de água fria e água quente foram mal coladas, estando as peças soltas, mesmo que embutidas na alvenaria. Foi necessária a substituição e correta execução de toda a instalação de água fria e 
DRANKA, J; MINIKOWSKI, W. ESTUDO DE CASO DA REABILITAÇÃO DE UM EDIFÍCIO MULTIPAVIMENTOS PARALISADO POR 4 ANOS NA CIDADE DE JOINVILLE-SC. $4^{\circ}$ Simpósio Paranaense de Patologia das Construções (40 SPPC), artigo 4SPPC107, pp. 48 - 58, 2019. DOI: $10.4322 / 2526-7248.028$

água quente, podendo ser reaproveitados apenas os registros e algumas tubulações de queda de água pluvial e esgoto da instalação.

A instalação sanitária se encontrava em boas condições dentro dos shafts, mas nos finais de coluna (pés de coluna), as conexões e algumas tubulações apresentavam trincas, deterioração, falta de prumo, ressecamento de anéis de vedação e caimento invertido, comprometendo o funcionamento (Fig.11). Pela ação da paralisação e pela má execução de alguns pontos, foi necessária a troca e correção da instalação nos locais em que ela se apresentava exposta e com problemas.

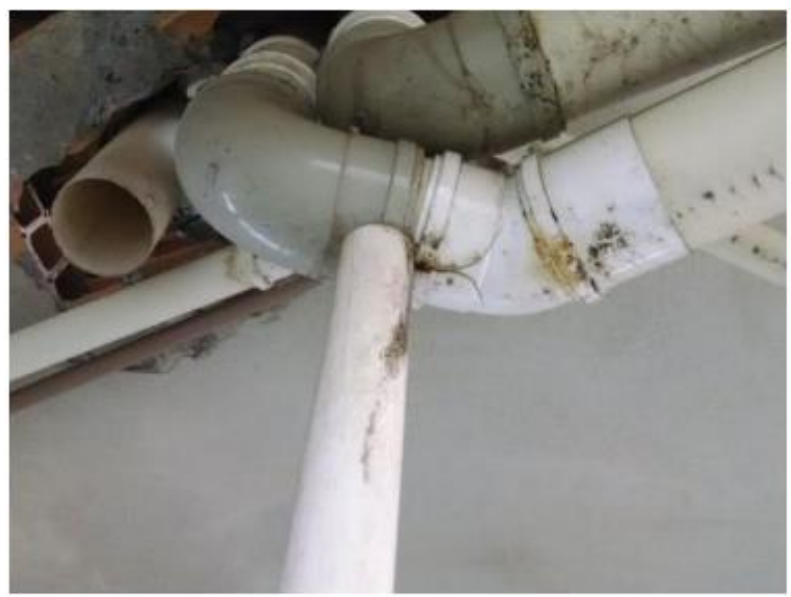

Figura 11: Deterioração da instalação sanitária.

\section{Conclusões}

O presente estudo de caso pôde apresentar os pontos afetados pela paralisação da construção de um edifício por 4 anos na cidade de Joinville - SC e as soluções adotadas para a recuperação. Os serviços estudados apresentaram problemas devido a exposição ao tempo pelo período de abandono da obra, mas teve o grau de dano aumentado pela má execução em sua construção.

Durante o estudo de caso, a recuperação da obra ainda estava sendo realizada e foi perceptível que, mesmo após levantamento de pontos afetados pela paralisação por meio de inspeção visual, elaboração de projetos para recuperação e planejamento das atividades, novos pontos podem surgir ou pode haver mudança na gravidade de pontos já analisados, sendo necessário alterações nos projetos e replanejamento da execução. Estas incidências evidenciam a importância do investimento feito durante a fase de inspeção e avaliação da edificação abandonada.

A decisão de recuperação de uma edificação abandonada e inacabada leva em consideração diversos fatores como: disponibilidade de recursos a serem investidos, mudança de função da edificação, grau de melhorias a serem adotadas e viabilidade de execução da recuperação. Este conjunto define o produto a ser apresentado ao final da obra e a valorização que pode ser agregada à edificação reabilitada. 
DRANKA, J; MINIKOWSKI, W. ESTUDO DE CASO DA REABILITAÇÃO DE UM EDIFÍCIO MULTIPAVIMENTOS PARALISADO POR 4 ANOS NA CIDADE DE JOINVILLE-SC. $4^{\circ}$ Simpósio Paranaense de Patologia das Construções (40 SPPC), artigo 4SPPC107, pp. 48 - 58, 2019. DOI: 10.4322/2526-7248.028

O fato de uma edificação sofrer um processo de recuperação ou reabilitação é algo que deve ser arquivado e fazer parte da documentação da obra, sendo de ciência de seus proprietários atuais e futuros o histórico de sua construção, os pontos afetados e as soluções adotadas. O processo de recuperação e reabilitação impacta na vida útil da edificação e as informações sobre procedimentos que precisaram ser executados é essencial para resolver eventuais problemas futuros.

As soluções adotadas para a recuperação de serviços de estrutura, alvenaria de vedações, revestimento argamassado e instalações prediais do edifício foram condizentes com normas e recomendações da bibliografia tanto para má execução de serviços quanto para a ação do tempo sobre uma obra paralisada e inacabada.

Cada caso de recuperação e de manifestação patológica é único, devendo ser analisado com atenção e em detalhes antes de qualquer decisão. Podem ser encontradas semelhanças entre diagnósticos, manifestações patológicas e estado de obras abandonadas, sendo interessante o conhecimento das soluções adotadas para a recuperação, mas considerando todos os fatores que diferenciam os casos e influenciam no resultado.

\section{Agradecimentos}

Agradecemos ao responsável técnico da obra em estudo pela adesão ao trabalho, disponibilidade, atendimento e dedicação, bem como à Universidade do Estado de Santa Catarina e demais profissionais e acadêmicos que de alguma forma contribuíram para a realização deste artigo.

\section{Referências}

[1] CROITOR, E. P. N. (2008) A gestão de projetos aplicada à reabilitação de edifícios: estudo da interface entre projeto e obra. Dissertação (mestrado), Escola Politécnica da Universidade de São Paulo, São Paulo, Brasil.

[2] AZEVEDO, M. T. de. (2011) Patologia das Estruturas de Concreto. In: ISAIA, G. C. (Ed). Concreto: Ciência e Tecnologia. São Paulo, São Paulo, Brasil, 2:10951128.

[3] TIMERMANN, J. (2011) Reabilitação e Reforço de Estruturas de Concreto. In: ISAIA, G. C. (Ed). Concreto: Ciência e Tecnologia. São Paulo, São Paulo, Brasil, 2:1175-1210.

[4] SOUZA, V. C. M. de; RIPPER, T. (1998) Patologia, recuperação e reforço de estruturas de concreto. São Paulo, São Paulo, Brasil.

[5] VIANA, T. (2016) Manifestações patológicas e recuperação de estruturas de concreto armado na PHC Rio Palmeiras, Revista Especialize On Line, 1:1-14.

[6] MUNARO, R.; POSSAN, E. (2017) Análise da Falha de Concretagem de Pilares de uma Edificação: Estudo de Caso, Revista Técnico-Científica do CREA-PR. Edição especial:1-15. 
[7] GROCHOSKI, M. (2008) Sistemas de reparo para estruturas de concreto com corrosão de armaduras, Boletim Técnico da Escola Politécnica da USP. 1-23.

[8] TAGUCHI, M. K. (2008) Avaliação e Qualificação das Patologias das Alvenarias de Vedação nas Edificações. Dissertação (mestrado), Universidade Federal do Paraná, Curitiba, Brasil.

[9] GALDINO, L. R. N.; SILVA, A. L. da; ALVES, D. M. de L.; MELLO, M. F. B. W. C. de; GOMES, T. C. P.; GONZAGA, G. B. M. (2016) Estudo de Caso: Patologias Mais Recorrentes nas Residências da Comunidade Rafael, Ciências Exatas e Tecnológicas, 3:107-120.

[10] PACHECO, C. P.; VIEIRA, G. L. (2017) Análise Quantitativa da Degradação das Fachadas com Revestimento Cerâmico, Cerâmica, 63:432-445.

[11] NASCIMENTO, R. E. (2014) Patologia das Construções Devido ao Tempo de Uso: Ênfase em Instalações. Monografia (especialização), Universidade Tecnológica Federal do Paraná, Curitiba, Brasil. 